\title{
Titanium and Titanium Alloy Surface Structure Effects on Osteoblast
}

\author{
Hongwan Sun \\ School of Medicine \\ Dalian University \\ Dalian, China \\ E-mail:959673243@qq.com
}

\author{
Ling Tang \\ School of Life Science and Technology \\ Dalian University \\ Email: tangyuling6688@163.com
}

\author{
Jingying Zhang * \\ School of Medicine \\ Dalian University \\ Dalian, China \\ E-mail:jingyingzhang2014@foxmial.com \\ *corresponding author: Jingying Zhang
}

\begin{abstract}
To investigate the effectiveness of Titanium and Ti6Al7Nb surface by the mechanical grinding and sanding acid etch on mouse osteoblastic adhesion, proliferation and differentiation. In Titanium and Ti6Al7Nb surface by mechanical grinding and sanding acid corrosion are different processing to prepare a smooth surface and rough surface with holes, SEM and EDX analyze titanium surface morphology and elemental composition, laser confocal microscopy analyze surface roughness of titanium plate and a three-dimensional structure, inductively coupled plasma spectrometer to measure the internal elements of titanium and titanium alloy precipitation, observe different titanium surface adhesion of osteoblast cells by scanning electron microscope and analyze the proliferation of osteoblast by MTT test. Our results showed that sandblasted etched titanium surface treated to form a porous structure, the roughness of the surface is much larger than mechanical polishing, the precipitation of element content among titanium and titanium alloys is minimal in simulated body fluid, osteoblastic adhesion, proliferation, differentiation on titanium surface with Sandblasted etching group is much better than the mechanical grinding group. In summary, two methods could promote osteoblastic adhesion, proliferation and differentiation, but sandblasting etching group is better than mechanical grinding group, while in sandblasting etching treatment group Ti6Al7 Nb is better than Titanium.
\end{abstract}

Keywords-Ti; Ti6-Al7-Nb; sandblasting etching; osteoblast; mechanical grinding

\section{INTRODUCTION}

With the rapid development of global economy, titanium (Ti) and titanium alloy has been used in all aspects of biological medicine, such as orthopedic implants, plastic surgery, dental restorations and planting, etc. In recent years, titanium is widely used in oral medicine due to good biocompatibility, good corrosion resistance, good physical and chemical properties and processing performance and good mechanical properties [1]. Titanium and titanium alloys change implant surface chemical composition, surface morphology, roughness by surface modified research which is benefit to the combination of bone-implant ${ }^{[2]}$. Sandblasting etching is a non-coating surface treatment method, titanium is imparted etching technology after sandblasting, thus sheet sets nest holes large cavity forms a secondary hole in the surface of the titanium. To observe mouse osteoblasts in different processed $\mathrm{Ti}, \mathrm{Ti} 6 \mathrm{Al} 7 \mathrm{Nb}$ surface adhesion and proliferation by in vitro experiments.

\section{MATERIALS AND METHODS}

\section{A. Sample preparation}

Experiment chooses two samples were $\mathrm{Ti}$, Ti6Al7Nb, the sample size is $14 \mathrm{~mm}$ in diameter and $1 \mathrm{~mm}$ in thickness. Put six titanium plate from each group into anhydrous ethanol and acetone in ultrasonic cleaning after $30 \mathrm{~min}$ rinsed with distilled water and dried. Samples were polished with following series silicon carbide papers of No. 800, 1500 and 2000 grit and abraded dirt layer and the oxide layer on the surface to form a surface with smooth, bright and no large scratches. Ti, Ti6Al7Nb were taken three respectively under $0.2 \mathrm{MPa}$ pressure for sandblasting $30 \mathrm{~s}$. The samples after sand blasting were ultrasonic cleaned with anhydrous ethanol and distilled water for $30 \mathrm{~min}$ with distilled water, concentrated sulfuric acid and concentrated hydrochloric acid by 11:12: 2 configurating etching solution. $\mathrm{Ti}$, Ti6Al7Nb respectively etching 80 s, then were ultrasonic cleaned with anhydrous ethanol and distilled water for $30 \mathrm{~min}$. S1 for TI mechanical polishing, $\mathrm{S} 2$ for $\mathrm{Ti6} \mathrm{Al} 7 \mathrm{Nb}$ mechanical grinding group, SLA1 for Ti sandblasting acid erosion group, SLA2 Ti6Al7 $\mathrm{Nb}$ sandblasting acid erosion group.

\section{B. Roughness of the sample}

Three sample of four groups were placed with a laser confocal stents, then roughness and three-dimensional structures of sample surface were analyzed by $3 \mathrm{D}$ laser scanning confocal microscope.

\section{SBF configuration}

The SBF was prepared by dissolving reagent-grade chemicals of $\mathrm{NaCl}, \mathrm{NaHCO}_{3}, \mathrm{KCl}, \mathrm{K}_{2} \mathrm{HPO}_{4} \cdot 3 \mathrm{H}_{2} \mathrm{O}, \mathrm{MgCl}_{2} \cdot 6 \mathrm{H}_{2} \mathrm{O}$, $\mathrm{CaCl}_{2}$ and $\mathrm{Na}_{2} \mathrm{SO}_{4}$ into deionized water buffering at $\mathrm{pH} 7.40$ with tris-hydroxymethyl-aminomethane $\left(\left(\mathrm{CH}_{2} \mathrm{OH}\right)_{3} \mathrm{CNH}_{2}\right)$ and 1.0 $\mathrm{mol} / 1 \mathrm{HCl}$ at $37^{\circ} \mathrm{C}$. It is shown in TABLE 1 .

\section{ICP measurement}

Four samples were soaked in $30 \mathrm{ml} \mathrm{SBF}$ for $7 \mathrm{~d}, 14 \mathrm{~d}, 21 \mathrm{~d}$, $28 \mathrm{~d}$, then taking $3 \mathrm{ml}$ from each group to measure by inductively coupled plasma emission spectrometer (optima 2000DV).

\section{E. Mouse osteoblastic primary culture}

Take 3d newborn mice with neck sudden death into $75 \%$ alcohol disinfection for $5 \mathrm{~min}$, separate calvaria bone after DHank's liquid rinsing and scrape periosteal and connective tissue. Clean skull bone using DMEM and cut up. It was supplemented with $0.25 \%$ trypsin and digested for $20 \mathrm{~min}$ at $37^{\circ} \mathrm{C}$. After suck out digestive juice, using $1 \mathrm{mg} / \mathrm{ml}$ Type II collagenase to digest 
for $20 \mathrm{~min}$ at $37{ }^{\circ} \mathrm{C}$, then centrifuge, discard the supernatant, add DMEM medium containing $15 \%$ serum and pipet bone pieces. After that cell suspension was seeded in culture flasks to culture in the thermostat fulfill of $\mathrm{CO}_{2}$ at $37{ }^{\circ} \mathrm{C}$.

\section{F. Identification method of osteoblast}

Osteoblasts were seeded at a density of $1 \times 10^{5}$ cells $/ \mathrm{cm}^{2}$ in 24-well plate, which were placed in the thermostat for $30 \mathrm{~min}$ at $37{ }^{\circ} \mathrm{C}$ and cell morphology was observed under a microscope.

\section{G. Cell adhesion}

The cells were seeded at a density $1 \times 10^{4}$ on the mechanical polishing and sanding acid corrosion group of $\mathrm{Ti}$ and $\mathrm{Ti}$ i6 $\mathrm{Al} 7 \mathrm{Nb}$. After cultured for $3 \mathrm{~d}$, cell adhesion situation was observed by scanning electron microscopy (SEM).

\section{H. Cell proliferation}

Two samples from Ti and TI6Al7Nb were placed in 24-well plates, the cells were seeded at a density $1 \times 10^{4}$ on titanium plate. $500 u l$ of MTT solution was added to each well and cultured at $37^{\circ} \mathrm{C}$, after 1,3 and 5 days, the absorbance of solution was measured at a wavelength of $570 \mathrm{~nm}$

\section{The morphology of the sample surface and elemental composition analysis}

The morphology of the mechanical polishing and sanding acid corrosion group of $\mathrm{Ti}$ and $\mathrm{Ti} 6 \mathrm{Al} 7 \mathrm{Nb}$ was observed using high resolution field Scanning Electron Microscope(NOVA
NanoSEM450), the elemental composition of the sample surface was analyzed using EDX.

\section{RESULTS}

\section{A. Sample surface characteristics and elemental composition analysis}

Define abbreviations and acronyms the first time they are used in the text, even after they have been defined in the abstract. Abbreviations such as IEEE, SI, MKS, CGS, sc, dc, and rms do not have to be defined. Do not use abbreviations in the title or heads unless they are unavoidable.

Smooth-Ti (S1) and smooth-Ti6Al7Nb (S2) groups can be seen, the surface of mechanical polishing is smooth and consistent stripes scratches. SLA-Ti (SLA1) and SLATi6A17Nb (SLA2) groups may indicate titanium surface after sandblasting etched has a large number of primary pores and secondary pores with 2-8 um in diameter, which size is differ, depth is not uniform, the shape is irregular, as the opening of the semicircle with sharp edges. Occasionally in micron holes can see nanoscale holes, which increase the porous morphology of the surface. SLA1 group is mostly flat circular holes, while SLA2 group is mostly elongated holes with slightly rounded morphology (Fig .1). Fig .2 shows that after sandblasting and etching of titanium surface, the elemental composition of titanium plate itself no major change, it can be neglected in the experimental range.
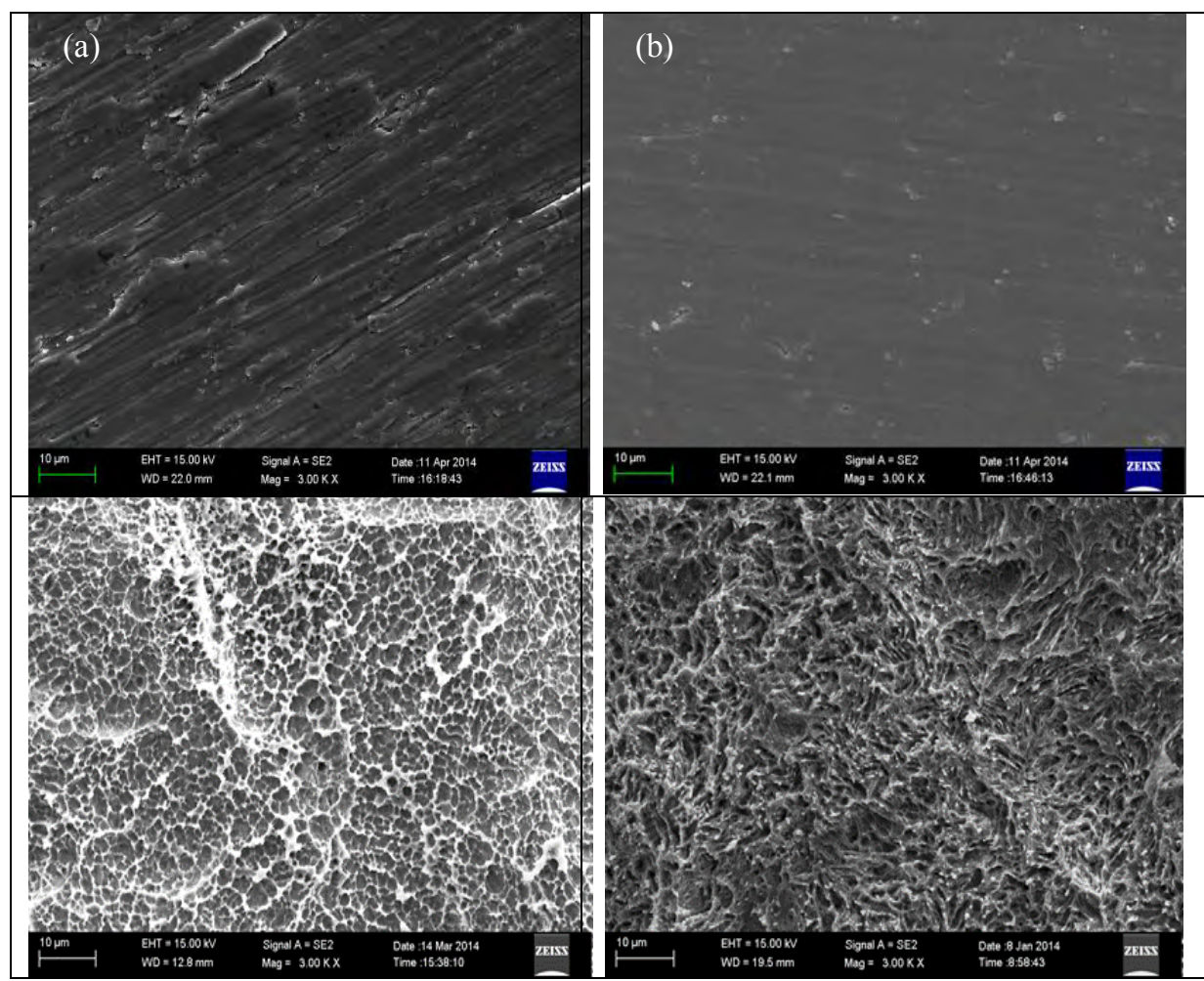

Figure 1. SEM images showing the morphology of surfaces (a)S1, (b)S2, (c)SLA1, (d) SLA2 


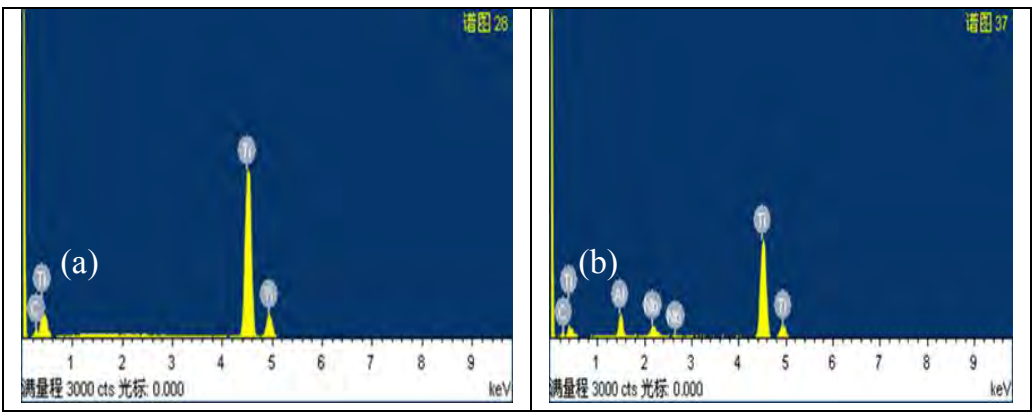

Figure 2. Elemental composition analysis of surfaces :(a)SLA1, (b)SLA2

B. Roughness and the three-dimensional structure of the sample surface

The roughness of S1, S2, SLA1, SLA2 surface is shown in table 2 . The roughness of not sandblasting etching is small, while roughness of the surface after blasting etching is greatly

(a)

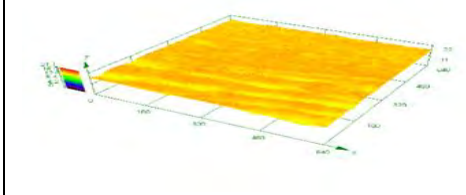

(c)

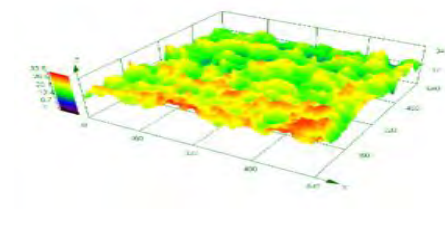

improved, which Ti6Al7 $\mathrm{Nb}>\mathrm{TI}$. Three-dimensional structure for not blasted acid etched titanium only show mechanical scratch without holes forming, but sandblasting etched titanium has obvious dimple-like structure with more rough surface morphology (Fig .3).

Figure 3. Three-dimensional structure of samples (a)S1,(b) S2,(c) SLA1,(d) SLA2

\section{Internal elements of samples precipitated content}

$\mathrm{Ti}, \mathrm{Al}, \mathrm{Nb}$ elements precipitate from $\mathrm{Ti}$ and $\mathrm{Ti} 6 \mathrm{Al} \mathrm{Nb}$ were shown in Fig .4. TI was soaked in SBF for 7, 14, 21, 28 days at $37{ }^{\circ} \mathrm{C}$, precipitation amount of $\mathrm{Ti}$ element was $0.0109 \mathrm{mg} / \mathrm{l}$, $0.0151 \mathrm{mg} / \mathrm{l}$ and $0.0153 \mathrm{mg} / \mathrm{l}$, after 28 days Ti element was almost no precipitate. Whlie $\mathrm{Ti}$ element precipitates steadily from

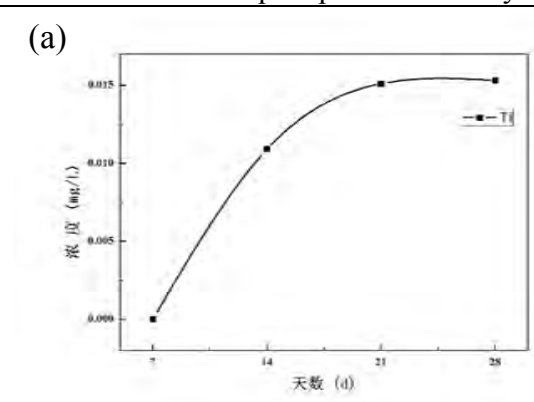

(b)

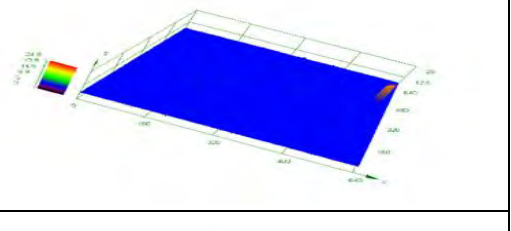

(d)

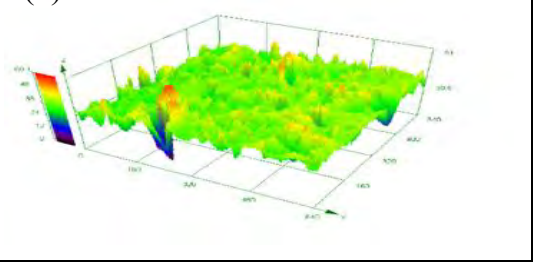

Ti6Al7 $\mathrm{Nb}$ at 28 days. $\mathrm{Al}$ precipitation reached a peak at 14 days, afte that it gradually reduced, but $\mathrm{Nb}$ element has not been deposited. Thus the amount of $\mathrm{Ti}, \mathrm{Al}, \mathrm{Nb}$ precipitate into bone tissue around the implant is very litter within the experimental range. It has almost no destruct for implant-osseointegration, but its long-term impact needs further study.

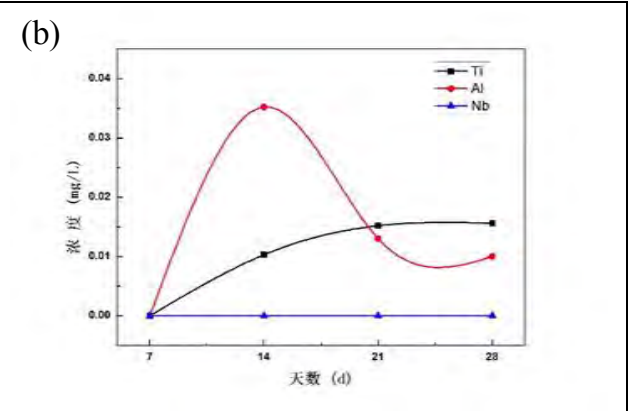

Figure 4. Internal elements of TA1 and TC20 precipitated content:(a)TA1,(b)TC20

\section{Result of osteoblastic identification}

Osteoblastic growth in mice have different short or long type of spindle and fusiform under 100 times the electron microscope with obvious nucleolus (Fig .5).

\section{E. Cell adhesion}

Osteoblasts were inoculated in four groups, after three days the shape of it was shown by SEM (Fig .6). S1 and S2 groups showed cells of the smooth titanium surface were simply adsorbed, while osteoblasts firmly adhered to the titanium surface in SLA1 and SLA2 groups, cell filopodias extend to the size of 
the holes in the titanium plate, which SLA2 group has more than SLA1 group.

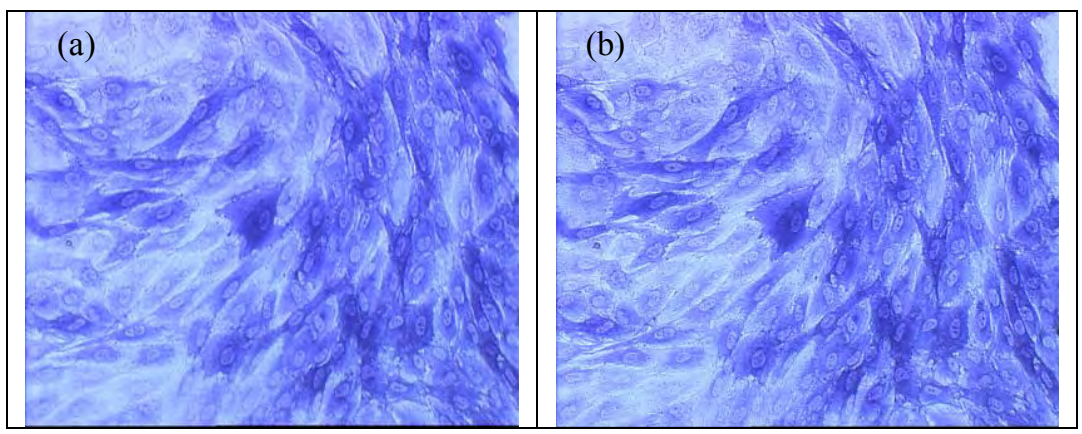

Figure 5. Electron microscopy showing the structure of mouse osteoblastic cells

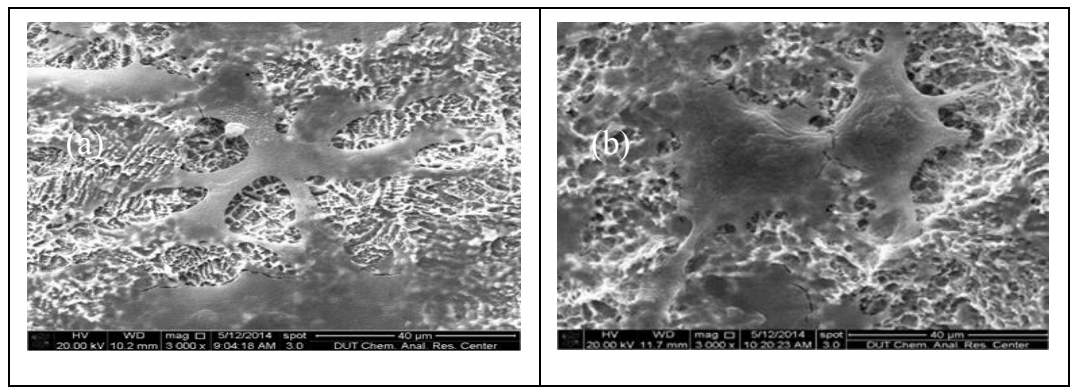

Figure 6. SEM images showing osteoblastic adhesion in the different treatment of different titanium surface: (a)S1,(b) S2,(c) SLA1,(d) SLA2

\section{F. Cell proliferation}

As was showed in Fig .7 the OD value of Ti and Ti6Al7Nb with SLA were significantly increased than the smooth group ( $p$
$<0.05$ ), among this, Ti6Al7Nb is slightly higher than $\mathrm{Ti}$ after culture 1 day. After cultured for 3 and 5 days, osteoblasts in $\mathrm{Ti}$, Ti6A17Nb surface with a higher cellular proliferation $(\mathrm{P}<0.05)$.

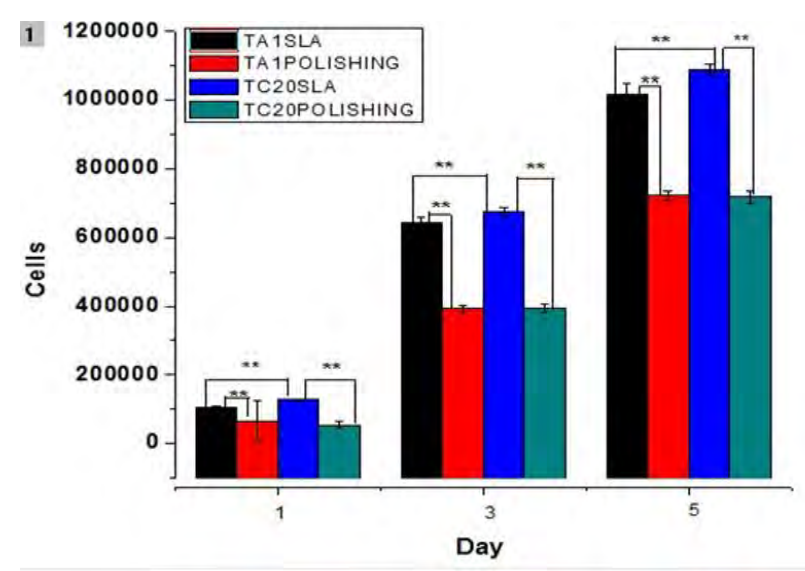

Figure 7. The table showing osteoblastic proliferation

\section{DISCUSSION}

The size of the implant surface pores has long been considered one of the most important factors. Current research about implant - osseointegration mainly through surface modified treatment. Experiments can be seen roughness of simple mechanical polishing for implant surface is less than $0.5 \mathrm{um}$ (Ra $<0.5 \mathrm{um}$ ), while Ra value of sandblasting etching is about $3 \mathrm{um}$. It increases the roughness of implant surface, thereby increases the area of the implant surface, increases bone-derived cells adhesion and makes implant and bone integrate better, rough ridge grooves play a mainly role on the organization ${ }^{[3]}$. Szmukler-Moncler et al. in vitro experiments show that the implant surface after sandblasting etching with interlocking ability ${ }^{[4]}$.
TI and TI6AL7NB soaking in SBF can be seen the precipitated amount of elements is very litter in the range of experimental result. With the increase of days the content of $\mathrm{Al}$ element is lower, this could be the result of oxidation, so $\mathrm{Al}$ toxicity almost can be ignored in the experiment. The chosen cells are osteoblasts, mainly due to the osteoblast cells can promote bone growth. Cells can be grown in the pores which greater than 200um in earlier studies ${ }^{[5]}$. Recent studies have found that the small size of the hole in favor of osteoblastic function, small size of the cavity can increase the roughness of $\mathrm{Ti}$ surface, it is conducive to cell adhesion. When the size of the hole is smaller than the diameter of the cell, Zhang et al. reported that the pored diameter of $\mathrm{TiO}_{2}$ surface is about 3um, it helps to improve the adsorption capacity of MC3T3-E1 cells ${ }^{[6]}$. On the 
other hand Popat et al. proved when the hole is less than $70 \mathrm{~nm}$ cell adhesion ability will decline ${ }^{[7,8]}$.

It can be observed by SEM, compared with the simple mechanical polishing, after sandblasting etching treatment, micron-sized holes will be formated for titanium surface, osteoblasts are better spreading in the SLA surface, wherein osteoblasts of Ti6Al7Nb surface is better than TI, osteoblastic pseudopodia can preferably depth to Ti6Al7Nb holes, it is in favor of inducing bone combine and make the implantosseointegration closely. Dong Fei et al. reported that the roughness of titanium surface in favor of increasing osteoblastic adhesion $^{[9]}$. MTT assay showed that SLA group is better than S group, in SLA groups Ti6Al7Nb is better than Ti, which shows cell proliferation gradually increase with the number of days increasing. Wei Yanping et al. confirmed that the surface with sandblasting acid etching can better promote proliferation and expression of functional activity of bone cells than smooth surface by experiments ${ }^{[10,11]}$.

\section{CONCLUSIONS}

Sandblasting etching treatment can increase the roughness of $\mathrm{Ti}$ and $\mathrm{Ti} 6 \mathrm{Al} 7 \mathrm{Nb}$ surface, then form micron holes. It can increase the contiguous area between implant surface and can be conducive to osteoblastic adhesion and proliferation, while osteoblastic adhesion and proliferation of Ti6Al7 $\mathrm{Nb}$ surface with sandblasting etching is significantly better than other experimental groups. But what kind of implant surface modification are the most conducive to implant-bone combination has to be further research.

TABLE I. ION CONCENTRATIONS OF THE SBF AND HUMAN BLOOD PLASMA.

\begin{tabular}{|l|c|c|}
\hline \multirow{2}{*}{ Ion } & \multicolumn{2}{|c|}{ Ion concentrations(mmol/I) } \\
\cline { 2 - 3 } & Blood plasma & SBF \\
\hline $\mathrm{Na}+$ & 142.0 & 142.0 \\
\hline $\mathrm{K}+$ & 5.0 & 5.0 \\
\hline $\mathrm{Mg}^{2+}$ & 1.5 & 1.5 \\
\hline $\mathrm{Ca}^{2+}$ & 2.5 & 2.5 \\
\hline $\mathrm{Cl}^{-}$ & 103.5 & 147.8 \\
\hline $\mathrm{HCO}_{3}{ }^{-}$ & 27.0 & 4.2 \\
\hline $\mathrm{HPO}_{4}{ }^{2-}$ & 1.0 & 1.0 \\
\hline $\mathrm{SO}_{4}{ }^{2-}$ & 0.5 & 0.5 \\
\hline $\mathrm{PH}$ & $7.2-7.4$ & 7.4 \\
\hline
\end{tabular}

TABLE II. THE ROUGHNESS OF TITANIUM AND TITANIUM ALLOY SURFACE.

\begin{tabular}{|c|c|}
\hline \multicolumn{2}{|c|}{ Roughness of titanium and titanium alloy surface } \\
\hline group & $\boldsymbol{R a}($ um $)$ \\
\hline polishing-Ti & 0.301 \\
\hline polishing-Ti6Al7Nb & 0.118 \\
\hline SLA-Ti & 2.727 \\
\hline SLA- Ti6Al7Nb & 3.333 \\
\hline
\end{tabular}

\section{ACKNOWLEDGMENT}

The Liaoning Province Department of Education Foundation in China (2013481), Dalian Science and Technology Project in China (2013E11SF057), China Postdoctoral Science Foundation (2014M551097), and Liaoning Province Postdoctoral Start Foundation in China (20141198) supported this study.

We are grateful to SUNTEC Titanium Co., Ltd., Dalian, Liaoning Province,China for providing titanium and titanium alloy materials.

\section{REFERENCES}

[1] CraigRG , PowersJM . Dental restorative materials science[M]. Xinyi Zhao, Chao Yi Translate. Xian: World Book Publishing, 2006.

[2] Shanchang Li, Dechao Li. The status quo about immediate titanium implant-bone combination promote ways. Heilongjiang Pharmaceutical Sciences, 2008, 31 (5),pp.62-63

[3] HuangHH, Ho CT, Lee TH, et a.l Effect of surface roughness of ground titanium on initial cell adhesion. Biomol Eng, 2004, 21(3 /5): 93-97.

[4] Szmukler-Moncler S, Perrin D, Ahossi V, et al. Biological properties of acid etched titanium implants: effect of sandblasting on bone anchorage. J Biomed Mater Res B Appl Biomater, 2004, 68(2),pp.149-159

[5] W. Xue, B.V. Krishna, A. Bandyopadhyay, et al., Processing and biocompatibility evaluation of laser processed porous titanium, Acta Biomaterialia 3 (6) (2007)1007-1018

[6] Z. Zhang, J. Sun, H. Hu, et al., Osteoblast-like cell adhesion on porous silicon-incorporated $\mathrm{TiO}_{2}$ coating prepared by micro-arc oxidation, Journal of Biomedical Materials Research Part B: Applied Biomaterials 97 (2) (2011)224-234.

[7] K.C. Popat, L. Leoni, C.A. Grimes, et al., Influence of engineered titania nanotubular surfaces on bone cells, Biomaterials 28 (21) (2007) 3188-3197.

[8] M.J. Biggs, R.G. Richards, M.J. Dalby, Nanotopographical modification: a regulator of cellular function through focal adhesions, Nanomedicine 6 (5) (2010)619-633.

[9] Fei Dong, ZhongJuan Ding, Tao Niu. Study about the influence of surface oxide film and osteoblastic growth of $\mathrm{TiO}_{2}$ with sandblasting etching [J]. Huaxi Stomatology, 2008, 1: 10 -141.

[10] [Zheng Fan, Suang Jia, Jiansheng Sun. The roughness of titanium surface impacts osteoblasts core factor $\alpha 1$ subunit gene expression. Chinese Journal of Stomatology, 2010,45(8),pp.466-470.

[11] Yanping Wei, Xaojie Wang, Xiaojie Ma et al. Ti6-Al4-V activity and wear-resistant coating impact the biological behavior of osteoblasts. Journal of Clinical Stomatology, 2006, 22(10),pp.587589 . 